This is an author produced version of a paper published in International Journal of Sexual Health. This paper has been peer-reviewed but does not include the final publisher proof-corrections or journal pagination.

Citation for the published paper:

Plantin, Lars; Wallander, Lisa; Mannheimer, Louise. (2017). Public knowledge and attitudes to HIV : Research from three decades in Sweden. International Journal of Sexual Health, vol. 29, issue 1, p. null

URL: https://doi.org/10.1080/19317611.2016.1193080

Publisher: Taylor \& Francis

This document has been downloaded from MUEP (https://muep.mah.se) / DIVA (https://mau.diva-portal.org). 


\title{
Public Knowledge and Attitudes to HIV: Research From Three Decades in Sweden
}

\author{
Lars Plantin $^{\mathrm{a}}$, Lisa Wallander ${ }^{\mathrm{a}}$, and Louise Mannheimer ${ }^{\mathrm{b}}$ \\ ${ }^{a}$ Department of Social Work, Malmö University, Malmö, Sweden; 'bearning, Informatics, Management and Ethics, Tomtebodavägen, Karolinska \\ Institutet, Stockholm, Sweden
}

\begin{abstract}
The overarching objective of this article is to describe the Swedish public's knowledge about HIV and attitudes toward people living with HIV during the period 1987-2011. Within the framework of this objective, the article also directs a special focus at the association between knowledge about HIV transmission and attitudes toward people who are HIV positive. The study is based on the results of a questionnaire sent to a stratified random sample on eight occasions between 1987 and 2011. The study population comprises the Swedish general public aged 16-44 and is stratified on the basis of the respondents' age, with each of five age groups (16-17, 18-19, 20-24, 25-34, and 35-44) comprising $20 \%$ of the study respondents. A total of 21,027 individuals have completed the questionnaire in the eight surveys. The survey instrument is relatively short and comprises 27 questions on knowledge, attitudes and sexual behaviour relating to HIV. The eight surveys show that the public's knowledge about HIV and its different transmission routes is high and has increased over time. Above all there has been an increase in the level of knowledge about how HIV is not transmitted between people. However, the public's knowledge about the infectiousness of individuals receiving treatment for HIV infection is low. Public attitudes toward people with HIV have also undergone a clear shift over time, toward increased tolerance and a decline in the level of fear, especially in social situations. Despite this, a residual suspicion and stigmatisation can be seen in the public's attitudes to people who are HIV positive. This is most obvious from the questions that link HIV to sexuality and here the changes are very modest over time. Public knowledge about HIV and its transmission routes has increased between 1987 and 2011. Attitudes toward people who are HIV positive have generally become more tolerant and positive, not least in relation to different social situations. The fear of becoming infected has declined. At the same time there remains a stigma, which continues to direct suspicion at people who are living with HIV and to ascribe them negative characteristics and behaviors that are based on prejudice. The results show, however, that the public's attitudes toward same-sex relationships are clearly more accepting today than they were previously, and that the symbolic association between HIV and this group is tending to become weaker.
\end{abstract}

\section{ARTICLE HISTORY}

Received 13 October 2015

Revised 28 March 2016

Accepted 18 May 2016

\section{KEYWORDS}

HIV; HIV positive; general public; attitudes; knowledge

\section{Introduction}

It is now 34 years since the first individual was diagnosed with HIV in Sweden. Despite initial fears of an explosive infection scenario, it can now be noted that the prevalence of HIV in Sweden has been low and has consistently remained at a level of under 0.1 percent (Public Health Agency of Sweden [PHA], 2014). Since 1981, over 11,200 individuals have been diagnosed with HIV and there are currently just over 6,800 people living with the virus in Sweden (PHA, 2014). A great deal has changed, however, over the course of this period for those who are HIV positive. First, rates of mortality and illness have been radically reduced by the new antiretroviral drugs. In 2014, 93\% of HIV patients in Sweden were receiving antiretroviral treatment and in this same year, only 35 individuals developed AIDS (PHA, 2014). Several studies conducted over recent years have also shown that these medications reduce the risk of transmitting the virus to others (Del Romero, Castilla, Hernando, Rodríguez, \& García, 2010; Loutfy et al., 2013; Reynolds et al., 2011; START, 2015). As early as in 2008, the Swiss AIDS Commission argued that individuals who were HIV positive could in principle be regarded as noninfectious if they were receiving wellmanaged antiretroviral therapy (Vernazza, Hirschel, Bernasconi, \& Flepp, 2008), although the relevant Swedish authorities did not make a similar statement until five years later (SMI, 2013b). This means that the majority of those infected with HIV can today, albeit subject to certain side effects and limitations, live a long life in the absence of serious complications. At the same

CONTACT Lars Plantin Lars.plantin@mah.se E Department of Social Work, Malmö University, Nordenskioldsgatan 8, Malmö, Sweden 20506. 
time, it is reasonable to ask whether these developments are also reflected in the public's view of HIV. What knowledge do people have of the changes that have occurred in relation to HIV over the past three decades, and how do the public view people who are living with HIV today? In the 1980s, the illness quickly became the focus of a substantial level of fear, suspicion, and negative attitudes among the public, both in Sweden and abroad (Brorsson \& Herlitz, 1988; Sontag, 1988). To improve people's knowledge about HIV and to combat the continued stigmatisation of people who were HIV positive, government agencies implemented a number of national information campaigns during the 1980s (Henriksson, 1987). Since that time, no special efforts have been introduced with a focus on the public in general. Instead, HIV prevention measures have been concentrated to four specific groups: young people (Tikkanen, Abelsson, \& Forsberg, 2011), immigrants from countries with high levels of HIV infection, men who have sex with men (Tikkanen, 2003, 2008, 2010; SMI, 2013a) and individuals living with HIV (PHA, 2015). Interest in the illness appears to have declined over time and the topic has more or less disappeared from the Swedish media debate (Socialstyrelsen, 2007). But does this silence surrounding HIV mean that the level of suspicion directed at those who are HIV positive has also declined?

Against this background, the overarching objective of this article is to describe the Swedish public's knowledge about HIV and their attitudes toward people living with HIV during the period 1987-2011. Within the framework of this objective, we also direct a special focus at the association between knowledge about HIV transmission and attitudes toward people who are HIV positive. The study is based on a unique data set, comprising eight waves of a large national survey conducted repeatedly between 1987 and $2011(N=21,027)$. These data provide us with a unique opportunity to examine the public's HIV-related knowledge and attitudes over a period of 25 years.

To our knowledge, there are few studies in the international Anglo-Saxon research literature that have examined public knowledge about and attitudes toward HIV over time. ${ }^{1}$ One exception is found in the work of Herek, Capitanio, and Widaman (2002),

\footnotetext{
${ }^{1}$ There are some similar studies on knowledge and attitudes to HIV in a few other European countries, i.e. Germany and Switzerland. However, as none of these have been translated into English, it has not been possible to compare the results.
}

which followed the perceptions of the American public in this area during the 1990s. They noted that, over time, the level of public knowledge about the most common ways in which HIV is transmitted between people had increased considerably. At the same time they could see an increase in answers describing incorrect HIV transmission routes. Thus there was a tendency toward a polarization in terms of the public's knowledge about HIV. Similar findings were reported from a more recent series of British studies, which were conducted repeatedly during the period 20002014 (National AIDS Trust [NAT], 2007, 2010, 2014). Here it was also found that fears regarding social contacts with people who were HIV positive declined substantially over time, but that some negative attitudes toward this group nonetheless remained in 2014. In addition, only $20 \%$ of the respondents in the final wave of the study knew that the level of infectiousness was minimal among individuals undergoing wellmanaged antiretroviral treatment. This final study of the series also showed a clear association between knowledge about HIV and attitudes toward those living with HIV. Eigty-four percent of those who knew the three most common transmission routes also agreed with the statement that "people with HIV deserve the same level of support and respect as people with cancer." The corresponding proportion among those who did not know about these transmission routes was 39\% (NAT, 2014).

Against the background of the studies carried out in the United States in the 1990s (Hetek, Capitano, \& Widman, 2002) and in Britain between 2000 and 2014 (NAT, 2014), it is of interest to examine the trends in the public's knowledge and attitudes toward HIV over the entirety of the relevant period, from the decade when HIV and AIDS were first diagnosed until the present decade. Our Swedish data-which have been collected on eight different occasions since 1987, using approximately identical methods and measures-provide us with a unique opportunity to do this.

\section{Method}

\section{Participants}

The study population comprises the Swedish public aged 16-44. The survey consisted in a postal questionnaire sent to a stratified random sample on eight occasions between 1987 and 2011. Half of these survey waves were based on a sample of 6,000 individuals, the rest on a 
sample of 4,000 individuals. The samples were all drawn using the SPAR register (a national register of the Swedish population) and were stratified on the basis of the respondents' age, with each of five age groups (16-17, $18-19,20-24,25-34$, and $35-44$ ) comprising $20 \%$ of the study respondents. The choice of narrower age bands for the younger age groups was based on several considerations. When the study was first set up (in the middle of the 1980s), about $90 \%$ of all clinically reported HIV-positive individuals in Sweden were below the age of 45 (see Herlitz \& Brorsson, 1990). Therefore, the age stratification was initially intended to allow for a comparison of young adults with adults in later phases of their lives. The decision to focus on the younger population, when the study was set up in the mid-1980s, was made with the intention of providing a greater amount of information about young people since they were regarded to be engaged in risky sexual behaviours more often than others. This is apparently a contradiction as young people in Sweden were not, and have never been, a dominant group in the statistics of people who contract HIV. However, in the event of a more general infection scenario for $\mathrm{HIV}$, at that time, young people's great tendency not to use condoms and their overrepresentation in the chlamydia statistics were seen as important reasons for a stronger focus on this cohort of the general public.

A total of 21,027 individuals have completed the questionnaire in the course of the eight survey waves between 1987 and 2011( $N$ for $1987=2,878,1989=$ 2,727, $1994=2,474,1997=2527,2000=3,528,2003$ $=2518,2007=3,011,2011=1,364)$. The age distribution among the respondents has generally been relatively even across the different survey waves (given the age-based stratification of the sample), whereas the gender composition of the samples has been somewhat more uneven, with a higher proportion of female than male respondents (due to the presence of a somewhat higher proportion of men among the nonrespondents). The educational level of the survey samples has increased successively, with $14 \%$ of the respondents having a university education in 1987, and $29 \%$ having a university education in 2011 . The proportion of individuals in employment or study has varied over the years: In 1987, 57\% of respondents were in employment and $33 \%$ were studying, whereas the corresponding figures for 2011 were $43 \%$ and $44 \%$, respectively. In the latest survey, in 2011, which was the first time that respondents were asked about their ethnic background, 13\% had been born abroad and $12 \%$ had one or two parents born abroad. This is in line with the general situation in Sweden, where the proportion of the population born abroad was $15 \%$ in 2012 (SCB, 2015).

\section{Measures}

The survey instrument is relatively short and comprises 27 questions on knowledge, attitudes, and sexual behaviour relating to HIV. The focus in this article is directed at the questions on knowledge and attitudes. The questionnaire was first tested in a smaller survey in 1986 (Brorsson \& Herlitz, 1987) and was then adjusted to the basic design it has today. However, over the 25 years that the study has continued, some questions have been excluded as they became irrelevant while other questionnaire items have been added. Questions on antiretroviral drugs and on communication with sexual partners about HIV were first included in the 1997 survey, for example. Most of the questions are followed by a 4-point response scale ranging from 1 (yes, definitely/completely agree) to 4 (no, definitely not/completely disagree).

\section{Procedure}

All of the surveys between 1987 and 2007 were carried out in the form of a paper-and-pencil questionnaire. In the 2011 survey, the respondents were also given the opportunity to complete the questionnaire digitally, and $31 \%$ of the respondents made use of this opportunity. The response rate has varied across the different years of the survey. In the 1980s, the response rate was around $70 \%$ for each survey, while during the period 1994-2003 it lay at just over $60 \%$. In 2007 the response rate declined to a little over $50 \%$ and then fell to $25 \%$ in 2011 . We have chosen to include data from all waves of the survey in this article, since the objective is to provide a picture of trends and tendencies over time (for a more detailed analysis and discussion of the low response rate in 2011, see Wallander, Tikkanen, Mannheimer, Östergren, \& Plantin, 2015).

The results presented below are based on univariate and bivariate analyses. First, to examine the public's knowledge and attitudes between 1987 and 2011, we conducted univariate analyses (percentages) for each of 17 knowledge or attitude items/questions, for each of the survey data sets in which a given item was included. Because the sample is stratified on the basis of age, the percentages presented in the first two tables have been weighted to correspond to the actual proportion of the 
population that is comprised of the different age groups. These tables do not include any significance tests (because the sizes of our samples, ranging between 1,364 and 3,528, would mean that even the smallest difference would be statistically significant). Instead, we focus on the broader patterns of stability and change in percentages between 1987 and 2011.

Second, to examine the association between knowledge and attitudes, we generated three new dichotomous variables based on (a) the respondents' knowledge about four of the suggested (but incorrect) transmission routes for HIV (four items), (b) their attitudes toward a hypothetical work colleague or schoolmate infected with HIV (three items), and (c) their response to the statement that people with HIV should refrain from sexual intercourse (one item). The first of these variables was constructed by assigning the value 1 to the respondents who shared the belief that HIV certainly or probably can be transmitted via tears, public toilets, saliva, or insects (these are all incorrect transmission routes), and the value 0 to the remaining respondents (including the "don't knows"). The second variable was constructed by assigning the value 1 to the respondents who would (in response to a hypothetical work colleague or schoolmate being infected with HIV) certainly or probably change job/school, demand a separate toilet for the infected person, or avoid close contact with this person, and the value 0 to the remaining respondents (including the "don't knows"). The third variable was constructed by assigning the value 1 to the respondents who completely or partly agreed with the statement that people with HIV should refrain from sexual intercourse, and the value 0 to the respondents who completely or partly disagreed with the statement (including the "can't decides"). Subsequently, we ran cross-tabulations to examine whether the respondents' knowledge about incorrect transmission routes was associated with (a) their attitudes toward a work colleague or schoolmate infected with HIV, and (b) their responses to the statement that people with HIV should refrain from sexual intercourse. The differences between the groups were compared using the Pearson Chi-Square test, and the strength of the associations was assessed using the Phi coefficient. In this article, we present two figures based on the results from the cross-tabulations.

The study has been approved by the regional research ethics review board (Dnr. 2011/11).

\section{Results}

\section{Public knowledge about HIV: Trends over time}

The eight surveys show that the public's knowledge about HIV and different transmission routes increased during the period 1987-2011. As can be seen from Table 1, there is a consistently high level of awareness that HIV is transmitted sexually, via blood and from a mother to the fetus. Around 90\% of the respondents knew this and in these respects the figures are relatively stable over time, although we can also see a tendency that more people in 2011 than in 1987 did not believe that HIV is transmitted through semen and vaginal secretions. The major changes are instead seen in relation to the public's perceptions about other transmission routes. For example, the proportion who answered that kisses or saliva constitute possible transmission routes has declined substantially over time. Similarly, the proportion who stated that HIV can be spread via public

Table 1. The Swedish public's knowledge about HIV 1987-2011 (in \%).

\begin{tabular}{|c|c|c|c|c|c|c|c|c|}
\hline Knowledge & 1987 & 1989 & 1994 & 1997 & 2000 & 2003 & 2007 & 2011 \\
\hline \multicolumn{9}{|c|}{ HIV is definitely or probably transmitted (or alternatively "very or fairly high risk") via... } \\
\hline Semen & 92 & 93 & 93 & 92 & 92 & 91 & 87 & 81 \\
\hline Vaginal secretions & 89 & 91 & 88 & 89 & 88 & 87 & 83 & 76 \\
\hline Blood & 99 & 100 & 100 & 100 & 99 & 98 & 99 & 98 \\
\hline From pregnant woman to fetus & 87 & 94 & 95 & 91 & 90 & 89 & 90 & 83 \\
\hline Tears & 35 & 33 & 31 & 23 & 22 & 19 & 17 & 9 \\
\hline Public toilets & 26 & 18 & 16 & 12 & 14 & 16 & 10 & 13 \\
\hline Saliva & 64 & 64 & 58 & 52 & 49 & 48 & 42 & 30 \\
\hline Insects & 31 & 26 & 28 & 25 & 26 & 25 & 20 & 26 \\
\hline \multicolumn{9}{|l|}{ Antiretroviral drugs lead to people who are infected with HIV... } \\
\hline No longer being infectious & - & - & - & 0 & 0 & 0 & 1 & 1 \\
\hline Being less infectious & - & - & - & 7 & 10 & 13 & 14 & 17 \\
\hline Still being as infectious as they were without the drugs & - & - & - & 71 & 68 & 58 & 61 & 59 \\
\hline Don't know & - & - & - & 22 & 21 & 28 & 24 & 23 \\
\hline
\end{tabular}

Note. The figures have been weighted to correspond to the actual proportion of the population in different age groups (age span: 16 to 44 years). Size of full sample: $1987=2,878,1989=2,727,1994=2,474,1997=2,527,2000=3,528,2003=2,518,2007=3,011,2011=1,364$. 
toilets has halved. At the same time, $26 \%$ of respondents still viewed insect bites as a possible transmission route in 2011, and 30\% stated that the HIV virus in saliva is associated with a real risk for infection.

The five waves of the survey conducted between 1997 and 2011 included questions about the public's knowledge of infectiousness among individuals receiving treatment for HIV infection. As early as in the 1997 survey (i.e., 1 year after the medications had been introduced in Sweden), it was found that $86 \%$ of the public were aware of the new antiretroviral drugs. At the same time, however, most respondents thought that such treatment did not affect an individual's infectiousness. Seventy-one percent stated that infectiousness was not affected at all, and $22 \%$ stated that they did not know how the treatment affected infectiousness. Fourteen years later, in the 2011 survey, the picture remained largely the same. Fifty-nine percent stated that they thought that infectiousness remained unchanged by antiretroviral treatment and a similar proportion to that found in the 1997 survey, 23\%, stated that they did not know how the treatment affected infectiousness.

\section{Public attitudes toward people with HIV:- Trends over time}

In all of the questionnaires, the respondents were asked questions about how they would react if they came into contact with people who were infected with HIV. Here too there is a clear shift over time, toward increased tolerance and a decline in the level of fear. Table 2 shows, for example, that very few would today consider changing to a new school or workplace if they found out that somebody at school or work had HIV. Similarly, very few would demand that the infected individual was given a toilet of their own at the workplace or in school-this proportion declined from $40 \%$ in 1987 to $8 \%$ in 2011 . We can also see a substantial decline in the proportion who state that they would definitely or probably avoid close contact with a work colleague or schoolmate who was HIV positive from $54 \%$ in 1987 to $19 \%$ in 2011 . In the 2011 survey, $83 \%$ answered that they would definitely or probably learn more about the illness if they found out that a work colleague or schoolmate had HIV. This represents a decline by comparison with the 1987 survey, however, in which $93 \%$ responded in this way.

A further sign of increased tolerance among the public can be seen in relation to the question regarding views about a group that had quickly become linked to HIV. In the 1987 survey, 39\% stated that they completely or partly agreed with the statement that there is nothing abnormal about being a homosexual, whereas the corresponding proportion 20 years later, in 2007, was $76 \%$. At the same time as the general picture shows increased tolerance toward people with HIV, there is still some level of worry and suspicion among the public. In 2011, 19\% stated that they would definitely or probably avoid close contact with a schoolmate or work colleague who was infected with HIV. A residual suspicion and stigmatization can be seen when we look at the public's answers to the questions that link HIV to sexuality. In the 1997 survey, for example, only $29 \%$ believed that everyone or nearly everyone who is infected with HIV informs their partner that they have HIV. Twelve years later, in 2011, this figure had increased to $40 \%$, but the majority of the public thus still believed that people with HIV were concealing their HIV-status from their sexual partners. At the same time almost all respondents, 98\% in the 2011 survey, stated that people with HIV must inform their sexual partners about their condition. The prevalence of this view has remained constant since the 2003 survey. Many

Table 2. Swedish public's attitudes toward HIV 1987-2011 (in \%).

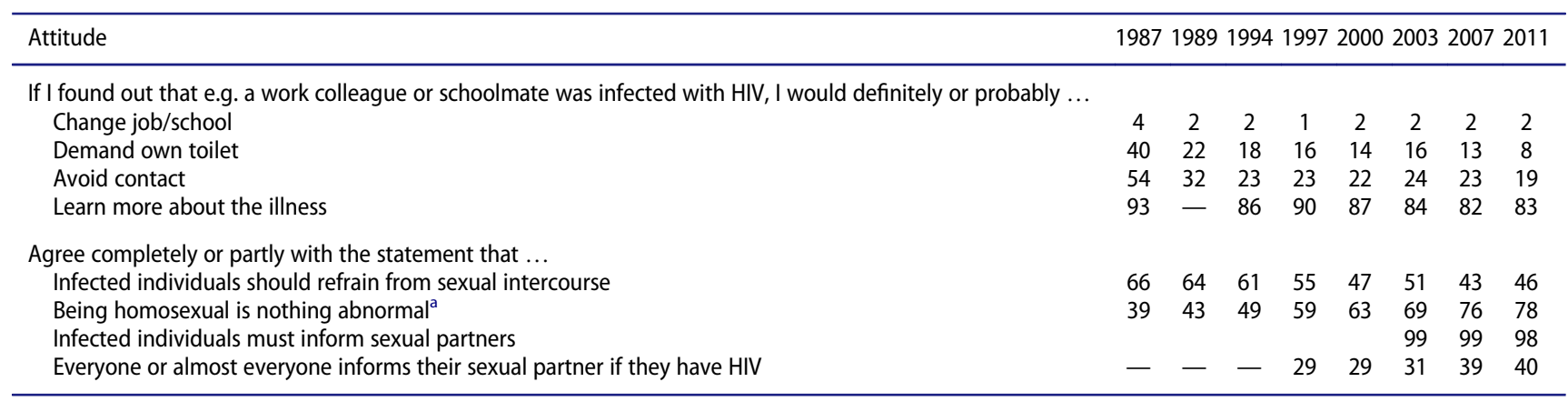

The figures have been weighted to correspond to the actual proportion of the population in different age groups (age span: 16 to 44 years). Size of full sample: $1987=2,878,1989=2,727,1994=2,474,1997=2,527,2000=3,528,2003=2,518,2007=3,011,2011=1,364$.

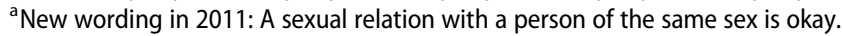


respondents also have a highly restrictive view of the rights of HIV-positive individuals to engage in various sexual activities. In 2011, for example, $46 \%$ stated that persons infected with HIV should refrain from sexual intercourse.

\section{The association between knowledge about incorrect transmission routes and attitudes to people infected with HIV}

Figures 1 and 2 present the results from cross-tabulations conducted on the material from each of the eight data sets (unweighted data). The general patterns that can be seen in the figures below also emerge when the data are weighted.

Figure 1 shows that individuals who believe that HIV can be transmitted via tears, public toilets, saliva, or insects have a greater propensity (than those who state that HIV cannot be transmitted in these ways, or who "don't know") to keep their distance from persons infected with HIV (change job/school, demand that an individual infected with HIV be given a separate toilet, or avoid close contact; for example, 67\% compared with $41 \%$ in 1987 , and $36 \%$ compared with 15 percent in
2011). For all of the analysed years, the differences between the groups are statistically significant (Pearson Chi-square $p$-value $<0.001)$, and the Phi coefficient ranges between 0.15 and $0.26(1987=0.23,1989=0.19$, $1994=0.18,1997=0.19,2000=0.15,2003=0.20$, $2007=0.26,2011=0.23$ ).

Further, Figure 2 shows that individuals who believe that HIV can be transmitted via tears, public toilets, saliva, or insects have a greater propensity (than those who state that HIV cannot be transmitted in these ways, or who "don't know") to feel that people infected with HIV should refrain from sexual intercourse (e.g., 68\% compared with $58 \%$ in 1987, and $60 \%$ compared with $40 \%$ in 2011). For all of the analyzed years, the differences between the groups are statistically significant (Pearson Chi-square $p$-value $<0.010$; for 1997 the $p$-value $=$ 0.012), and the Phi coefficient ranges between 0.05 and $0.19(1987=0.09,1989=0.06,1994=0.06,1997=$ $0.05,2000=0.08,2003=0.12,2007=0.14,2011=$ 0.19). An overall comparison between the results displayed in Figures 1 and 2 shows that knowledge about incorrect transmission routes for HIV is more strongly associated with the propensity to keep one's distance from persons infected with HIV than with the feeling

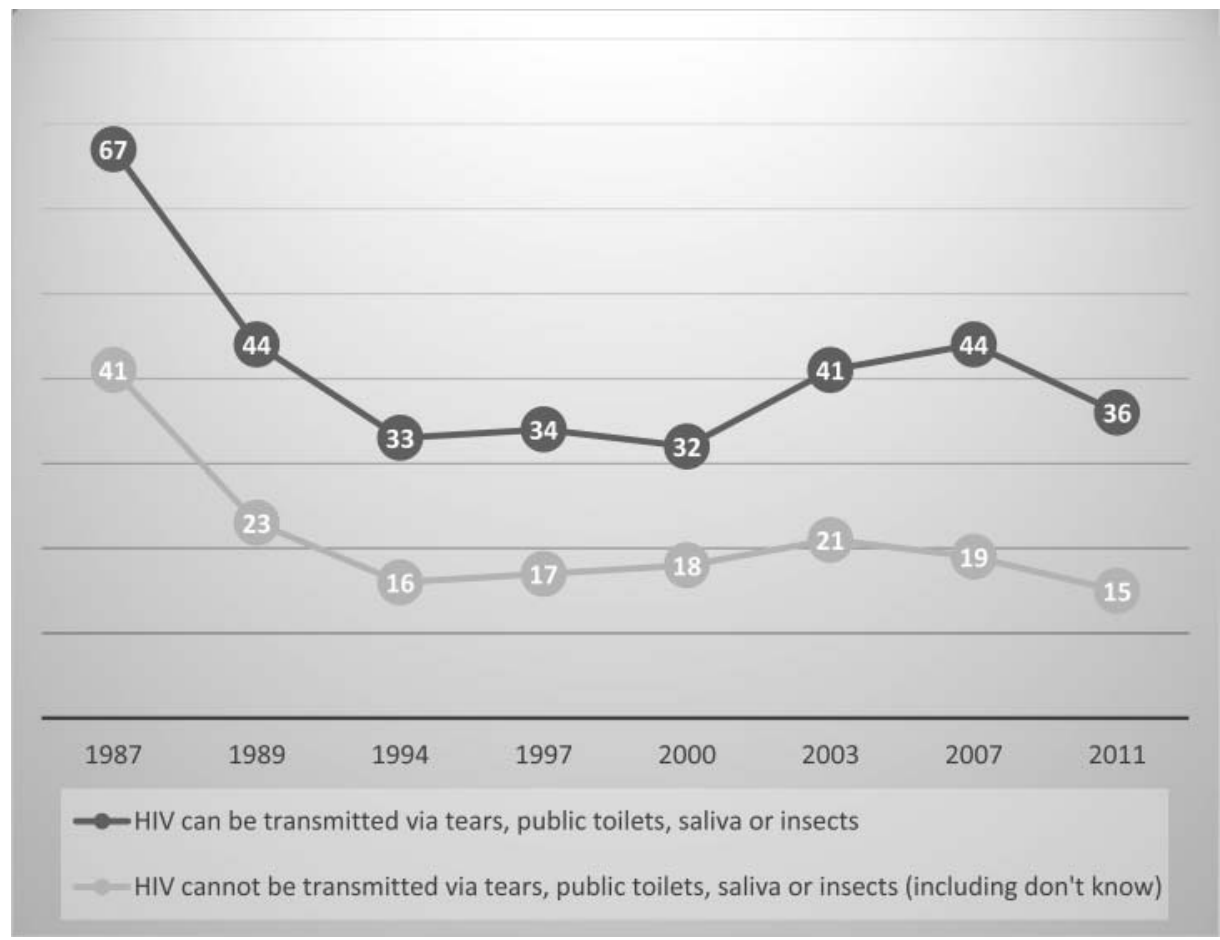

Figure 1. Proportion (in \%) of respondents who would change job/school, demand own toilet, or avoid close contact in response to a hypothetical work colleague or schoolmate being infected with HIV, for each of the eight data sets ( $N$ for $1987=2,849, N$ for $1989=$ $2,700, N$ for $1994=2,428, N$ for $1997=2,498, N$ for $2000=3,481, N$ for $2003=2,451, N$ for $2007=2,951, N$ for $2011=1,328$; unweighted figures). 


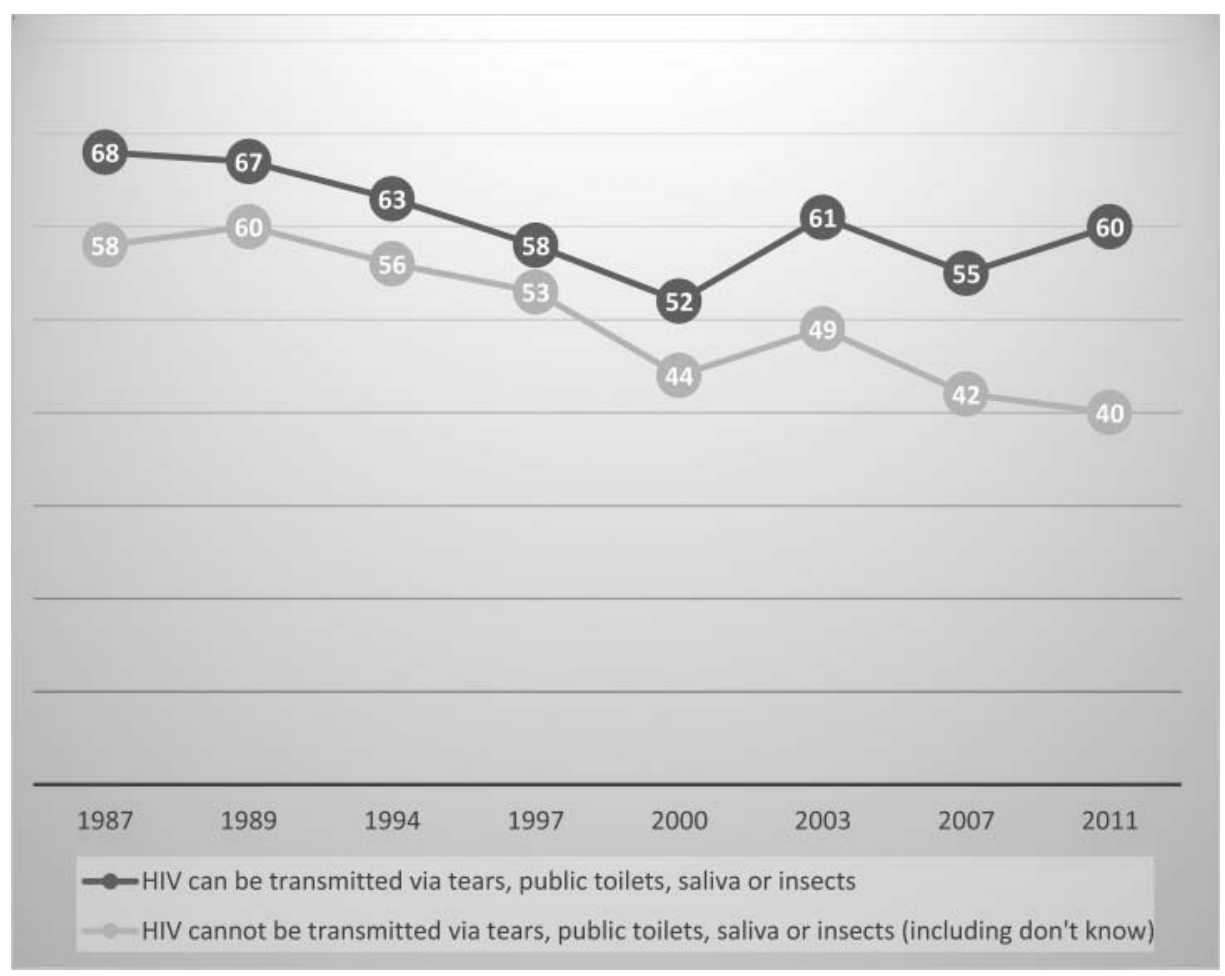

Figure 2. Proportion (in \%) of respondents who agree with the statement that people with HIV should refrain from sexual intercourse, for each of the eight data sets ( $N$ for $1987=2,844, N$ for $1989=2,696, N$ for $1994=2,423, N$ for $1997=2,486, N$ for $2000=3,469, N$ for $2003=2,486, N$ for $2007=2,979, N$ for $2011=1,336$; unweighted figures).

that people infected with HIV should refrain from sexual intercourse.

\section{Discussion}

The article's overarching objective has been to describe the Swedish public's knowledge about and attitudes toward HIV during the period 1987-2011. A secondary objective has been to examine the association between knowledge on the transmission of HIV and attitudes toward people who are HIV-positive. The study shows that the Swedish public has had a high level of knowledge about how HIV is actually transmitted throughout the period examined. Despite this we can see a tendency in the two most recent surveys, 2007 and 2011, toward fewer respondents stating that there is a fairly or very high risk that HIV can be transmitted via semen and vaginal secretions. It is unclear why this decrease has occurred. Additional and more specific studies must be undertaken in this area. It is also important, in future studies, to examine public awareness of HIV virus in other body fluids as the virus, for example, is not only transmitted through semen and blood (in case of injury) during anal intercourse but also through anal secretion (Zuckerman et al., 2004).

However, the level of knowledge about how HIV is not transmitted has also increased substantially between 1987 and 2011. The proportions stating that HIV can be transmitted via public toilets, tears, or saliva, for example, have decreased by more than half over the course of the period. In spite of this, however, 30\% of the public still (in 2011) stated that saliva constitutes a probable route for the transmission of HIV, whereas 26\% stated that HIV can be transmitted via mosquito bites. A similar pattern has been found in British and American studies, which also show that levels of public knowledge about how HIV is transmitted, and how it is not transmitted, are now high (Herek et al., 2002; NAT, 2014). In Sweden, however, the proportion of people reporting incorrect transmission routes is significantly higher than in Great Britain. The proportion of people stating that HIV can be transmitted via public toilets, for example, is 13\% in Sweden and 4\% in Great Britain, and the gap has been significant across all of the years compared (NAT, 2014).

In both Sweden and Great Britain, knowledge about infectiousness in connection with antiretroviral 
treatment is very low. In Sweden, $18 \%$ of respondents in 2011 agreed with the statement that antiretroviral drugs reduce infectiousness, whereas in Great Britain in 2014, $20 \%$ agreed with the statement that "the risk of someone who is taking effective HIV treatment passing on HIV through sex is extremely low." These figures are astonishingly low given that effective antiretroviral treatment has been available since the mid-1990s. At the same time, it is only in recent years that a number of scientific studies have been able to establish that antiretroviral medications produce a reduced risk for the transmission of infection (Del Romero et al, 2010; Loutfy et al, 2013; Reynolds et al., 2011; START, 2015). In Sweden, this did not happen until 2013 (SMI, 2013b).

Our study also shows that the public's attitudes toward people with HIV have generally become more tolerant and positive. Above all, the fear of socializing or working with people who are HIV positive has declined dramatically. The same pattern is also found over time in the British study, where the proportion who agreed with the statement "I would feel comfortable working with a colleague who had HIV," for example, increased from 57\% in 2005 to $67 \%$ in 2014 (NAT, 2007, 2010, 2014). The results also show, however, a residual suspicion and restrictive attitude toward people who are HIV positive. In our study from 2011, for example, $60 \%$ of the respondents shared the view that HIV-positive individuals do not tell their sexual partners about their HIV status, whereas $46 \%$ felt that people who are HIV positive should refrain from having sexual intercourse. There may be a number of explanations for the finding that such a high proportion of the public express fear and suspicion in relation to questions about HIV and sexuality. Our study shows, for example, that a large proportion lack knowledge about the effects of antiretroviral drugs on the risk for transmitting HIV, while we also see a clear association between misconceptions about transmission routes and negative attitudes toward people who are living with HIV. Similar results have been reported by earlier studies (NAT, 2010, 2014). At the same time, we might ask whether the high level of suspicion among the public regarding the propensity of people with HIV to inform their sexual partners about their illness is exclusively due to poor knowledge or whether there might be other explanations.

Herek (1999) argued that public attitudes of this kind, whereby people who are HIV positive are subject to suspicion and perceived as being untrustworthy, are grounded in a stigma whose roots go back to a time when the illness was explicitly linked to promiscuity, immorality, and to groups that were regarded as marginalized or who deviated from the broader public's view of normality. Herek differentiated between two different types of HIV-related stigma. The one, which he referred to as instrumental stigma, relates to the individual's fear of becoming infected by serious and deadly diseases. This may take the form of an exaggerated fear of coming into contact with viruses and bacteria and may manifest itself in an avoidance of certain locations or forms of contact. Examples of this in our study are when the respondents agree with the statement that "an HIV positive work colleague must have their own toilet," "I would avoid contact with an HIV positive work colleague," or "I think HIV is transmitted via public toilets." The other type of stigma, symbolic stigma, relates to a symbolic association between HIV and certain groups of individuals, primarily men who have sex with men, and is linked to a fear rooted in various prejudices about the character of people who are living with HIV. These prejudices may take the form of views about promiscuity, dishonesty, or unreliability. In our study, they manifest themselves in the answers on whether individuals who are HIV positive "should refrain from sexual intercourse," for example, or whether those who are HIV positive inform their sexual partners about their condition. Viewed in terms of Herek's (1999) arguments, we can see that levels of both types of stigma declined in Sweden during the period 1987-2011, but that levels of instrumental stigma declined more rapidly than those of symbolic stigma. This would mean that the fear of coming into contact with the HIV virus declines more quickly than levels of prejudice and negative attitudes toward people who are HIV positive. At the same time, our survey shows that levels of acceptance toward same-sex relationships have increased substantially over time. Seventy-eight percent of the public state that sexual relationships between persons of the same sex "are okay." This means that same-sex relationships have become increasingly normalized in Sweden and are no longer associated with HIV to the same extent as they were previously. Here, then, we find differences related to symbolic stigma between our study of the Swedish public and Herek's $(1999,2002)$ studies of the public in America.

The results presented in this article are based on univariate and bivariate analyses of a unique set of data, covering eight waves of surveys with large national samples of the Swedish population. Since the data were limited to questions about knowledge, attitudes, and behavior related to HIV (along with some general questions about the respondents' 
sociodemographic characteristics), they did not allow for more sophisticated analyses aimed at explaining the trends discussed above. Taking account of this limitation, our data have provided us with a unique opportunity to observe stability and change in the public's knowledge about and attitudes toward HIV from the decade when HIV and AIDS were first diagnosed until the present day.

\section{Conclusions}

Despite the fact that the level of public information measures has declined dramatically and that the mass media discussion of HIV has become successively quieter during the period 1987-2011, public knowledge about HIV and its transmission routes has increased over time. Above all there has been an increase in the level of knowledge about how HIV is not transmitted between people. However, the Swedish general public is still characterised by a high level of misinformation regarding HIV transmission by comparison with the UK. Attitudes toward people who are HIV positive have generally become more tolerant and positive, not least in relation to different social situations in which people meet individuals who are living with HIV. The fear of becoming infected, and the instrumental stigma linked to this fear, has declined. At the same time there remains an, albeit weakened, symbolic stigma, which continues to direct suspicion at people who are living with HIV and to ascribe them negative characteristics and behaviours that are based on prejudice. The results show, however, that the public has a significantly more accepting view of same-sex relationships today than was previously the case, and that the symbolic association between those involved in same-sex relationships and HIV is tending to become weaker.

\section{Acknowledgments}

The authors would like to thank Claes Herlitz, PhD, Associate Professor, who was responsible for the HIV in Sweden project until 2011. This study was approved by the Regional Ethical Review Board in Lund, Sweden.

\section{Funding}

This project was supported by the Swedish Institute for Communicable Disease Control (grant 359/2010 and 01-12380/ 2008), Stockholm, Sweden.

\section{References}

Brorsson, B., \& Herlitz, C. (1987). Kunskaper mm om hiv/aids $i$ befolkningen. Utvecklingen till och med maj 1987 [Knowledge etc about HIV/AIDS in the general population. Developments to 1987]. Uppsala, Sweden: Institutionen för Socialmedicin, Uppsala Universitet.

Brorsson, B., \& Herlitz, C. (1988). The AIDS epidemic in Sweden: Changes in awareness, attitudes and behavior. Scandinavian Journal of Medicine, 16, 67-71.

Del Romero, J., Castilla, J., Hernando, V., Rodríguez, C., \& García, S. (2010). Combined antiretroviral treatment and heterosexual transmission of $\mathrm{HIV}-1$ : cross sectional and prospective cohort study. BMJ, 340, c2205.

Henriksson, B. (1987). AIDS: Föreställningar om en verklighet [AIDS. Notions on a reality]. Stockholm, Sweden: Glacio Förlag.

Herek, G. M. (1999). AIDS and stigma. The American Behavioral Scientist, 42, 1106-1116.

Herek, G. M., Capitanio, J. P., \& Widaman, K. F. (2002). HIVrelated stigma and knowledge in the United States: Prevalences and trends, 1991-1999. American Journal of Public Health, 92, 371-377.

Herlitz, C., \& Brorsson, B. (1990). AIDS in the minds of Swedish people: 1986-1989. AIDS, 4, 1011-1018.

Loutfy, M., Wu, W., Letchumanan, M., Bondy, L., Antonio, T., Margolese, S., et al. (2013). Systematic review of HIV transmission between heterosexual serodiscordant couples where the HIV-positive partner is fully suppressed on antiretroviral therapy. PLos One, 8(2), e55747.

National AIDS Trust. (2007). Public attitudes towards HIV. Retrieved from http://www.nat.org.uk/Media\%20Library/ Files/PDF\%20documents/NAT-MORI-report.pdf

National AIDS Trust. (2010). Public knowledge and attitudes. Retrieved from http://www.nat.org.uk/media/files/publica tions/jan-2011-hiv-public-knowledge-and-attitudes.pdf

National AIDS Trust. (2014). Public knowledge and attitudes. Retrieved from http://www.nat.org.uk/media/Files/PDF\%20do cuments/Mori_2014_report_FINAL.pdf

Public Health Agency of Sweden. (2014). Hiv under 2014 [HIV in 2014]. Retrieved from www.folkhalsomyndigh eten.se

Public Health Agency of Sweden. (2015). Att leva med hiv $i$ Sverige-en studie om livskvalitet hos personer som lever med HIV [Living with HIV in Sweden-a study of the quality of life of people living with HIV]. Stockholm, Sweden: Folkhälsomyndigheten.

Reynolds, S. J., Makumbi, F., Nakigozi, G., Kagaayi, J., Gray, R. H., Waver, M., et al. (2011). HIV-1 transmission among HIV-1 discordant couples before and after the introduction of antiretroviral therapy. AIDS, 25, 473-477.

SCB. (2015). Fortsatt ökning av utrikes födda i Sverige [Continued increase in the proportion of people born abroad in Sweden]. Retrieved from www.scb.se/sv_/hitta-statistik/arti klar/fortsatt-okning-av-utrikes-fodda-i-sverige/

SMI. (2013a). EMIS 2010 Sverige. Svenska resultat frä den europeiska internetundersökningen EMIS 2010: en studie 
om män som har sex med män. [EMIS 2010 Sweden. Swedish results from the European internet survey EMIS 2010; a study about men who have sex with men]. Stockholm, Sweden: The Swedish Institute for Communicable Disease Control.

SMI. (2013b). Smittsamhet vid behandlad hivinfektion. Kunskapsunderlag fran Smittskyddsintitutet och Referensgruppen for Antiviral terapi [Infectivity at treated HIV infection]. Stockholm, Sweden: The Swedish Institute for Communicable Disease Control.

Sontag, S. (1988). AIDS and its metaphors. New York, NY: Picador.

Socialstyrelsen. (2007). HIV och Aids i Sverige. Kunskaper, attityder och beteenden hos allmänheten 1987-2007 [HIV in Sweden. Knowledge, attitudes and behaviours among the general public]. Stockholm, Sweden: Author.

START. (2015). Initiation of antiretroviral therapy in early asymptomatic HIV infection. The New England Journal of Medicine, 373, 795-807.

Tikkanen R. (2003). Risky business? En sociosexuell studie av män som har sex med män [Risky business? A sociosexual study of men who have sex with men]. Göteborg, Sweden: Institutionen för Socialt Arbete, Göteborgs Universitet.

Tikkanen, R. (2008). Person, relation och situation: riskhandlingar, hivtest och preventiva behov bland män som har sex med män [People, relationship and situations: risk behaviours, hivtesting and preventive needs among men who have sex with men]. Malmö, Sweden: Hälsa och samhälle, Malmö högskola.

Tikkanen, R. (2010). MSM-enkäten: riskhandlingar, hivtest och preventiva behov bland män som har sex med män [The MSM survey: risk behaviours; hivtesting and preventive needs among men who have sex with men]. Malmö, Sweden: Hälsa och samhälle, Malmö högskola.

Tikkanen, R. H., Abelsson, J., \& Forsberg, M. (2011). UngKAB09. Kunskap, attityder och sexuella handlingar bland unga [UngKAB09. Knowledge, attitudes and sexual behaviours among young people]. Göteborg, Sweden: Göteborgs universitet, Institutionen för socialt arbete.

Vernazza, P., Hirschel, B., Bernasconi, E., \& Flepp, M. (2008). HIV-infizierte Menschen ohne andere STD sind unter wirksamer antiretroviraler Therapie sexuell nicht infektio's [HIV-infected people free of other STDs are sexually not infectious on effective antiretroviral therapy]. Schweizerische A'rztezeitung, 89, 165-169.

Wallander, L., Tikkanen, R. H., Mannheimer, L. N., Östergren, P.O., \& Plantin, L. (2015). The problem of non-response in population surveys on the topic of HIV and sexuality: a comparative study. European Journal of Public Health, 25, 172-177.

Zuckerman, R. A., Whittington, W. L. H., Celum, C. L., Collis, T. K., Lucchetti, A. J. J., Sanchez, J. L. \& Coombs, R. W. (2004). Higher concentration of HIV RNA in rectal mucosa secretions than in blood and seminal plasma, among men who have sex with men, independent of antiretroviral therapy. Journal of Infectious Disease, 190, 156-161. 